\title{
Health Information on the Internet
}
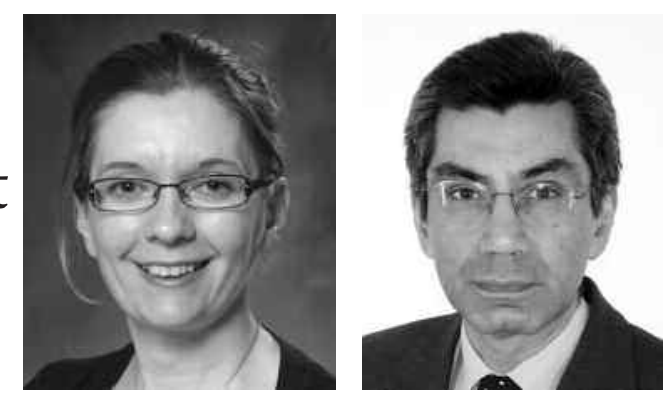

Writing on how we have adapted to accessing and acquiring information using the Internet, a recent article in the New Yorker asks us to consider this conundrum: Had the first Harry Potter book The Philosopher's Stone been published after rather than before the launch of Google, would the wizard-in-training be "Googling" for spells on a smart tablet rather than spending hours in the Hogwarts library searching for answers? ${ }^{1}$

The experience of a patient spellbound by health information gathered from the Internet arriving at a consultation is a familiar one. Responses to this situation vary, with only a few of us perceiving this as a challenge to our position. Most of us believe that it is the quality of the information that further influences the patient-physician relationship, the subsequent quality of care, and eventually health outcomes ${ }^{2}$. Prompted by such concerns about standards, many researchers have sought to quantify the quality of information on the Internet ${ }^{3}$. Not surprisingly, results have repeatedly shown that health information on the Net varies widely in accuracy and completeness, and in most instances, does not meet accepted standards of medical information as defined by the World Health Organisation Health on the Net (WHO-NET) standards ${ }^{4}$.

In a previous editorial in The Journal on this important subject, Deshpande and Jadad advised us that, like the public, we should move on and end our Byzantine discussions to measure health information on the Internet ${ }^{5}$. This aligns with our view: If we wish to preserve what we value most, namely our offline relationship with patients, we need to better understand and accept the cultural shift and to bring it into the clinic to the benefit of our patients.

It is in the context of this background that Singh, et al's descriptive study in this issue of The Journal should be viewed $^{6}$. This useful study replicates similar evaluations of YouTube content on conditions such as the H1N1 pandemic, cardiopulmonary resuscitation, and prostate cancer ${ }^{7,8,9}$. The methods used in all these studies have face validity and followed stringent criteria to evaluate the content of videos about these conditions posted on YouTube. The Singh study evaluated the first 200 of 3350 videos posted on YouTube, identified by using the search term Rheumatoid Arthritis.

Of these 200, they considered 102 to be appropriate for further evaluation. Most videos were posted from a group categorized as independent users: some were medical advertisements or postings from pharmaceutical companies, and, less frequently, from professional organizations and universities. Fifty-six of the 102 were considered useful, a number similar to that noted in other medical conditions. The best videos, those with high global quality score, were posted either by universities or professional organizations; those from pharmaceutical companies or medical advertisements and independent users had the lowest scores.

Most worrying was that 31 of the 102 uploads were deemed misleading; these were either advertisements or were promoted by for-profit organizations. Many of the misleading postings reviewed in this study advocated unconventional, non-evidence-based treatments, which were often based on unproven pathogenetic mechanisms. Unique to this study was an evaluation of the views of users, which showed that the likeability of videos rated lowest was similar to those rated most useful by the investigators.

Many solutions have been suggested to overcome the variable quality of health information on the Internet, such as those highlighted in the Singh article ${ }^{6}$. Suggestions include working with patients by educating them on how to search for health information and explaining the WHO-NET principles and tools ${ }^{10,11}$. With the pressures on our time it is unlikely that we can also undertake this role.

In the United States it is estimated that 245 million individuals access the Internet from some location, increasingly from mobile devices ${ }^{12}$. However, about one-quarter of Americans have no access to the Internet. Those divided from the digital world are more likely to be male, older,

\section{See YouTube for information on RA - A wakeup call?, page 899}

Personal non-commercial use only. The Journal of Rheumatology Copyright () 2012. All rights reserved. 
non-Caucasian, and poorer, as well as having lower educational attainment. Americans living with a disability are also less likely to have Internet access, further adding to their burden of disadvantage ${ }^{13}$. Sixty percent of those who do access the Internet seek information online for a medical disorder or problem. Not surprisingly, those with a chronic disorder are more likely to access medical information.

The most comprehensive survey of how Americans interrogate the Internet for health information is undertaken by the Pew Research Center and the most recent report, "The Social Life of Health Information," was published in May $2011^{12}$. Many of its findings have informed this editorial, but most salutary is the main conclusion that doctors and other health professionals remain the main and most important portal of choice for health information.

Few searching the Internet go directly to a medical portal or enter the websites of professional societies, but instead use a search engine ${ }^{14}$. Despite this approach, most consumers find the correct answers to medical questions ${ }^{14}$. Of the 5 conditions searched for most frequently on Web MD, 2 of them, gout and lupus, are within the domain of a rheumatologist. Eighty-six percent of users seeking drug information are more likely to want more detail on analgesics and corticosteroids, ranking among the top 5 questions on their health. Many of the respondents in this survey also found the Internet a valuable tool whether seeking a quick answer or attempting to gain a better understanding of treatment or drug options.

Despite concerns, there is little evidence that patients come to any harm from seeking information on the Internet, and as more people find they are helped rather than harmed, we need to embrace rather than shun seeking health information on the Internet ${ }^{12,13}$. Singh advises that we need to respond to this "pop-up," a phenomenon that is certainly here to stay, that cannot be blocked, and that would be at a mistake for doctors to ignore.

NICOLA ALCORN, Bsc, MBChB; RAJAN MADHOK, MD, FRCP, Centre for Rheumatic Diseases, Glasgow Royal Infirmary, Glasgow, United Kingdom

Address correspondence to Dr. Madhok.

E-mail: rajan.madhok@northglasgow.scot.nhs.uk

\section{REFERENCES}

1. Gopnik A. How the internet gets inside us. The New Yorker 2011; Feb 14;1-5.

2. Murray E, Bernard L, Pollack L, Donelan K, Catania J, Ken L, et al. The impact of health information on the internet on health care and the physician - patient relationship. National U.S. Survey among 1,050 US physicians. J Internet Res 2003:5:e17.

3. Purcell GP, Wilson P, Delamothe T. The quality of health information on the internet. BMJ 2002:324:557-8.

4. Health On the Net Foundation. The HON code of conduct for medicine and health. [Internet. Accessed February 10, 2012.] Available from: http://www.hon.ch/HONcode/Conduct.html

5. Deshpande A, Jadad AR. Trying to measure the quality of information on the internet: Is it time to move on? [editorial]. J Rheumatol 2009;36:1-3.

6. Singh AG, Singh S, Singh PP. YouTube for information on rheumatoid arthritis - A wakeup call? J Rheumatol 2012;39: 899-903.

7. Pandey A, Patni N, Singh M, Soud A, Singh G. YouTube as a source of information on the H1N1 influenza pandemic. Am J Prev Med 2010;38:e1-3.

8. Murugiah K, Vallakati A, Rajput K, Sood A, Challa NR. YouTube as a source of information on cardiopulmonary resuscitation. Resuscitation 2011;82:332-4.

9. Steinberg PL, Watson S, Stern JM, Deters L, Kowal B, Seigne J. YouTube as a source of prostate cancer information. Urology 2010;75:619-22.

10. National Library of Medicine. Information RX: A free information prescription program from the National Library of Medicine. [Internet. Accessed February 10, 2012.] Available from: http//www.informationrx.org

11. Fox S. The social life of health information, 2011. [Internet. Accessed February 10, 2012.] Available from: http://pewinternet.org/Reports/2011/Social-Life-of-health-info.aspx

12. Fox S. Americans living with disabilty and their technology profile. [Internet. Accessed February 10, 2012.] Available from: http://pewinternet.org/Reports/2011/social-life-of-health-Info.aspx

13. Eysenbach G, Kohler C. How do consumers search for and appraise health information on the World Wide Web? Qualitative study using the focus groups, usability test, and the in-depth interviews. BMJ 2002;323:573-6.

14. Smith R. Almost no evidence exists that the internet harms health. BMJ 2001;323:651.

J Rheumatol 2012;39:883-4; doi:10.3899/jrheum.120136 